\title{
STIRPAT-Based Driving Factor Decomposition Analysis of Agricultural Carbon Emissions in Hebei, China
}

\author{
Herui Cui, Tian Zhao*, Hongji Shi \\ Department of Economics and Management, North China Electric Power University, \\ Hebei 071003, China
}

Received: 12 July 2017

Accepted: 21 September 2017

\begin{abstract}
Low-carbon development has recently become a growing trend in agricultural modernization. It will provide beneficial guidance for exploring driving factors of agricultural carbon emissions in Hebei Province, a typical agricultural region, and formulate relevant policy on its reduction. Calculating carbon emissions in Hebei from 1995 to 2014 demonstrated that energy and land use accounted for more than $90 \%$ of agricultural carbon emissions, and there was an increasing tendency overall with a peak value in 2010 and, to a certain extent lately, a slight decline. This paper employed transformed Kaya identity in light of local actual conditions for selecting eight influencing factors. Meanwhile, the extended STIRPAT model and ridge regression were used to make regression analysis. Results showed that contributing factors were efficiency, agricultural import, urbanization, agricultural mechanization, and population, whose $1 \%$ increase caused $0.1852 \%, 0.1663 \%, 0.1597 \%, 0.1573 \%$, and $0.1329 \%$ increases in carbon emissions, respectively, while $1 \%$ growth in industry structure and agricultural affluence were responsible for $0.1475 \%$, and changing the elastic coefficient of $(0.1314-0.2958 \ln \mathrm{A}) \%$ decrease in carbon emissions, respectively, where A represented agricultural output value per capita. Furthermore, there existed an inverted U-shaped EKC between economic progress and carbon emissions. Given the above conclusions, policy recommendations were provided for effectively achieving agricultural carbon emissions reductions.
\end{abstract}

Keywords: agricultural carbon emissions, driving factors, Hebei, STIRPAT model, ridge regression

\section{Introduction}

Climate change, especially global warming, has been increasingly deteriorating, garnering wide-ranging attention all over the world [1]. The increase of greenhouse gas (GHG) emissions represented by carbon dioxide has

*e-mail: hszt1991@163.com been proven the foremost source of global "greenhouse effect" [2]. China, as the largest carbon emitter [3-4], joined the Paris Agreement in 2016 in order to work with other countries to cope with the greenhouse effect globally after 2020 [5]. It is the conventional perspective that secondary and tertiary industries are leading sectors of carbon emissions. Agriculture, however, with its rapid development rate, has become a significant impetus to grievous global warming [6]. Carbon emissions from the agricultural ecosystem have accounted for 
approximately $17 \%$ of China's total carbon emissions[7] - the second-largest source of GHG emissions [8]. Under this circumstance, it is essential for China, an agriculture power, to reinforce competence in dealing with the greenhouse effect in the field of agriculture and accomplish the target of carbon emissions reduction early.

Hebei Province is a national grain and edible oil producing area and is regarded as a major agricultural commodities supply base for the Beijing-Tianjin region, with more than 600 ten thousand hectares of arable land, ranking it fourth nationwide [9]. In the last 20 years, highspeed development has occurred in Hebei agriculture, whose output value has an average growth rate of $8.34 \%$ [10]. However, continuous advances in the agricultural economy, meanwhile, are conducive to unceasing augmentation of related carbon emissions. This conflict mainly arises from the fact that substantial consumption of agricultural energy and overuse of chemical fertilizers and pesticides have given rise to agricultural ecosystem degeneration. The eminent peculiarity of agriculture compared with other industries is that the alleviation of carbon emissions has a very powerful positive externality, including the amelioration of agricultural ecosystems and the enhancement of food quality.

Since it is meaningful to reduce agricultural carbon emissions, the $13^{\text {th }}$ Five-Year Plan (2016-20) for modern agricultural development in Hebei Province clearly indicated that [11] the government and relevant departments should effectively enhance the treatment of diffused pollution, optimize integration technology of agricultural machinery, reduce the application of pesticides and fertilizer detrimental to soil, and strengthen environmental monitoring in producing areas in order to realize the transformation of agricultural progress from extensive mode into intensive. Therefore, it is consequential to investigate factors driving agricultural carbon emissions in Hebei from a low-carbon perspective, and then propose vigorous measures directed against transforming the agricultural development pattern, which has realistic meaning for building low-carbon agriculture in Hebei Province.

More and more studies using various models to research agricultural carbon emissions and their related driving factors, including the Kaya identity, have been employed in carbon emissions because of its plain mathematical form, decomposition without residuals, and strong interpretation of influenced factors [12]. Besides, the STIRPAT model has also attracted broader attention as it considers diverse effects on environmental pressure when population, affluence, and technology change, respectively, and then eliminate errors of proportional changes in the original IPAT model [13]. Researches based on the Kaya identity and STIRPAT model to decompose factors of agricultural carbon emissions can be classified as national and provincial angles.

At the national level, on a basis of decomposition of agricultural energy and material input, Li et al. [14] concluded that the agricultural economy would propel carbon emissions to a large degree, and production efficiency, industrial structure, and rural labor would give inhibition. Yang [15] found that technological upgrading could increase carbon emissions for the short term and played a negative role in those on the whole by virtue of ameliorating carbon emission intensity. Dai et al. [12] made good use of the Kaya identity, and combined it with the LMDI model to introduce urbanization and rural living standards for a more comprehensive analysis of carbon emission ingredients. Yang [16] used the STIRPAT model from the eastern, middle, and western parts of China to analyze influencing factors, indicating that agricultural population and agricultural mechanization could promote carbon emissions while rural capital accumulation impairs them.

Research concerning agricultural carbon emissions at the national level gave macro conclusions that were not applicable in all regions because there was a noticeable diversity in economic advancement phases, population density, natural conditions, resource endowment, and scientific and technological levels across every province throughout China. Thus scholars continued to study more concretely on several representative provinces. Liu [17] used the Kaya identity for probing agricultural carbon emissions in Henan Province, indicating an increase in labor efficiency and production structure, and that the number of rural employee could cause a decrease in carbon emissions. On the contrary, agricultural economic progress reinforces these. Cao and Cao [18] separated carbon emissions into population, economic level, productivity, and industrial structure with transformed Kaya identity, finding that agricultural economic development played a foremost part in carbon emissions of agriculture in Jiangxi Province. Gao et al. [19] attempted to propose effective policy recommendations after finding elastic coefficients of total farming population, and that the agricultural contribution to gross output value were comparatively bigger in a logarithmic STIRPAT model when researching driving factors in Jilin Province. Similarly, according to the extended STIRPAT model, Liu and $\mathrm{Xu}$ [20] indicated there was a U-shaped EKC between economic growth and carbon emissions in Guangdong by analyzing driving factors of agricultural carbon emission intensity. It is apparent that differences of driving factors in influence on environmental pressure exist in diverse districts in China.

Dominating Hebei Province in terms of agriculture industry, relevant studies concerning agricultural carbon emissions are comparatively scanty. Based on statistics, Yuan et al. [21] found that overall carbon sequestration and emissions from farmland had gradually increased and that more carbon had been absorbed than emitted in the past 20 years (1989-2008) in Hebei Province. Xie [22] used the life cycle assessment model to investigate the carbon footprint and the structure of agriculture in Hebei Province, indicating that among all agribusiness departments, fertilizer manufacturing had the largest carbon footprint, followed by agriculture. Lu et al. [23] took advantage of the LMDI model to calculate quantity 
of carbon emissions due to agriculture commodities export, finding their strong correlation, and there was no EKC between carbon emissions and agricultural products export.

As aforementioned, current research focusing on driving factors of agricultural carbon emissions are primarily concentrated on China or some developed provinces. But few papers have probed into those of Hebei Province, a traditional agricultural region with severe air pollution and recent greenhouse effect problems. Therefore, it is crucial for scholars to precisely comprehend the driving mechanism of agricultural carbon emissions as much as possible. So, a further step in this paper is that in light of existing literature and based on Kaya identity transformation, driving factors concerning agricultural carbon emissions are decomposed into eight diverse elements involved in population, affluence, and technology aspects according to actual conditions in Hebei. Next, the extended STIRPAT model is utilized to make ridge regression, obtaining various influencing degrees of each factor, meanwhile testing if an inverted U-shaped EKC exists. Finally, conclusions and policy recommendations to boost low-carbon agricultural development in Hebei are presented based on results received. It is hoped that this paper can be drawn on for other regions analogous to Hebei in agriculture.

\section{Methodology}

\section{Measuring Agricultural Carbon Emissions}

Agriculture plays a key role in carbon emissions of Hebei Province. However, there have been no specific observations of them, with some statistics not being gathered. So, the estimation method was employed to calculate agricultural carbon emissions. On the ground of the formula for calculating agricultural carbon emissions in Hunan Province [24], the agricultural carbon emissions equation of Hebei Province is established as follows:

$$
\mathrm{C}=\sum \mathrm{C}_{\mathrm{i}}=\sum \mathrm{T}_{\mathrm{i}} \times \Omega_{\mathrm{i}}
$$

...where $C$ represents overall carbon emissions, $\mathrm{C}_{\mathrm{i}}$ denotes the carbon emissions of each source, $T_{i}$ is the quantity of each carbon source, $\Omega_{\mathrm{i}}$ is the emissions coefficient of each carbon source, and $i$ refers to species of carbon sources $(i=1,2, \ldots, n)$. Moreover, as the target of this paper is to study carbon emissions, so $\mathrm{CH}_{4}$ caused by paddy and livestock is to be converted to standard carbon. Based on the carbon footprint of agricultural carbon emissions, four major emission sources were classified as follows:

1) Carbon emissions attributable to agricultural land use includes agricultural material input (chemical fertilizer, pesticide, and plastic sheeting, etc.), farming activities, land cultivation, and other respects involved in carbon emissions (Table 1).
Table 1. Carbon emission coefficients of major carbon sources from land use.

\begin{tabular}{|c|c|c|}
\hline Source & Coefficient & Reference \\
\hline Chemical fertilizer $(\mathrm{kg} \mathrm{C} / \mathrm{kg})$ & 0.8956 & Xiong [1] \\
\hline Pesticide $(\mathrm{kg} \mathrm{C} / \mathrm{kg})$ & 4.9341 & Xiong [1] \\
\hline Plastic sheeting $(\mathrm{kg} \mathrm{C} / \mathrm{kg})$ & 5.18 & Tian [45] \\
\hline Cultivated land $\left(\mathrm{kg} \mathrm{C} / \mathrm{km}^{2}\right)$ & 312.6 & Wu [46] \\
\hline
\end{tabular}

2) $\mathrm{CH}_{4}$ emissions from the growing of paddy. Major crops in Hebei Province are maize, wheat, and paddy, of which $\mathrm{NO}_{2}$ is mainly emitted from maize and wheat [25]. As the direction of this paper is not all GHG emissions but carbon emissions definitely, the paddy (including early paddy, late paddy, and seasonal paddy) - a crucial source of $\mathrm{CH}_{4}$ emissions [26] - is the study priority of carbon emissions from crops. Based on Min [25], the kind of paddy in Hebei Province is chiefly seasonal paddy, its emission coefficient being $15.33 \mathrm{gCH}_{4} / \mathrm{m}^{2}$ [27]. On the basis of IPCC [28], the greenhouse effect caused by one ton of $\mathrm{CH}_{4}$ is equivalent to approximately 25 tons of $\mathrm{CO}_{2}$ (6.8182 tons of standard C).

3) Carbon emissions from livestock breeding mainly incorporates two aspects: $\mathrm{CH}_{4}$ emissions deriving from enteric fermentation and $\mathrm{CH}_{4}$ discharge from animal manure. Specifically in Hebei Province, the main livestock species generating $\mathrm{CH}_{4}$ are cattle, horse, donkey, mule, pig, goat, and sheep. The carbon emission coefficients of major types of livestock should use data from the national emission inventory of China, as the geography and breeding methods in China are different from other countries. However, there has been no national emission inventory of China concerning carbon emission coefficients of major types of livestock so far. So based on reference [25], this paper refers to the data from IPCC [29]. The discharge coefficients of livestock breeding are shown in Table 2.

Table 2. Carbon emission coefficients of major types of livestock ( $\mathrm{kg} \mathrm{CH}_{4} /$ head/year).

\begin{tabular}{|c|c|c|c|}
\hline Source & $\begin{array}{c}\text { Enteric } \\
\text { fermentation }\end{array}$ & $\begin{array}{c}\text { Emissions } \\
\text { from manure }\end{array}$ & Reference \\
\hline Cattle & 47 & 1 & IPCC [29] \\
\hline Horse & 18 & 1.64 & IPCC [29] \\
\hline Donkey & 10 & 0.9 & IPCC [29] \\
\hline Mule & 10 & 0.9 & IPCC [29] \\
\hline Pig & 1 & 4 & IPCC [29] \\
\hline Goat & 5 & 0.17 & IPCC [29] \\
\hline Sheep & 5 & 0.15 & IPCC [29] \\
\hline
\end{tabular}


Table 3. Carbon emission coefficients of major types of energy ( $\mathrm{kg} \mathrm{C} / \mathrm{kg})$.

\begin{tabular}{|c|c|c|}
\hline Source & Coefficient & Reference \\
\hline Diesel & 0.8636 & IPCC [47] \\
\hline Coal & 0.7476 & IPCC [47] \\
\hline Petrol & 0.5532 & IPCC [47] \\
\hline Electricity & 2.2132 & IPCC [47] \\
\hline
\end{tabular}

4) Fourth, carbon emissions produced by energy consumption in agriculture production. The extensive utilization of agricultural machinery such as farm irrigation and drainage machinery, water pump, harvester, truck, and tractor, etc. is a principle proportion of carbon emissions. Energy consumed by agricultural machinery mainly contains four categories: diesel, coal, petrol, and electricity (Table 3).

\section{Kaya Identity and STIRPAT Model}

To study influential factors of the environment, Ehrlich [30] first raised the IPAT model in 1971:

$$
\mathrm{I}=\mathrm{PAT}
$$

...where $I$ denotes environmental pressure (which refers to carbon emissions in this paper), $P$ represents total population, $A$ indicates affluence, and $T$ is technology. IPAT hypothesizes that $I$ is influenced equally proportionally by these certain driving factors, which is not in accordance with reality. Learning the limitation on IPAT, Dietz and Rosa [31] proposed an improved model named STIRPAT:

$$
\mathrm{I}=\mathrm{aP}^{\mathrm{b}} \mathrm{A}^{\mathrm{c}} \mathrm{T}^{\mathrm{d}} \mathrm{e}
$$

...where $I, P, A$, and $T$ are the same variables as those in Eq. (2); $a$ indicates the model coefficient; $b, c$, and $d$ are exponents of each independent variable; and $e$ refers to the random error term. Obviously, the STIRPAT model is a multivariable nonlinear stochastic model that is able to reflect nonlinear driving factors influence [4], and one defect of the original model is also settled in that $I$ is equally proportional to independent variables [32]. The natural logarithm form is shown in Eq. (4):

$$
\ln \mathrm{I}=\ln \mathrm{a}+\mathrm{bln} \mathrm{P}+\operatorname{cln} \mathrm{A}+\mathrm{d} \ln \mathrm{T}+\ln \mathrm{e}
$$

After transformation, the STIRPAT model becomes a linear form clearly to explain the connection between environmental pressure and relevant influenced elements.

According to the concept of elastic coefficient, when other variables are fixed, $P, A$, and $T$ vary by $1 \%$, respectively, resulting in $\mathrm{b} \%, \mathrm{c} \%$, and $\mathrm{d} \%$ change of $I$. Besides, the STIRPAT model is entitled to be extended by incorporating extra factors for researching more possible causes for environmental pressure [33].

As has been discussed, factors affecting environmental pressure may be classified as aspects of population, affluence, and technology. How to select influenced factors seems to be the key point of the whole study. Therefore, to obtain the extended STIRPAT model, this paper will combine with the Kaya identity to choose driving forces. Using the Kaya identity to establish a link between carbon emissions and factors of energy intensity, economy, and population was first proposed by Yoichi Kaya [34] at an IPCC conference in 1989. The original Kaya identity is specified as follows:

$$
\mathrm{CO}_{2}=\frac{\mathrm{CO}_{2}}{\mathrm{E}} \times \frac{\mathrm{E}}{\mathrm{GDP}} \times \frac{\mathrm{GDP}}{\mathrm{P}} \times \mathrm{p}
$$

Where $\mathrm{CO}_{2}$ denotes carbon emissions, $E$ illustrates energy consumption, GDP means gross domestic product, and $P$ demonstrates population. This model, as we can see, mainly takes energy impacts into consideration. For researching agricultural influence responsible for carbon emissions, it is considered to transform the Kaya identity, which is given by Eq. (6) in light of the study by Liu and $\mathrm{Xu}$ [20]:

$$
\mathrm{C}=\frac{\mathrm{CO}_{2}}{\mathrm{AI}} \times \frac{\mathrm{AI}}{\mathrm{AG}} \times \frac{\mathrm{AG}}{\mathrm{AP}} \times \frac{\mathrm{AP}}{\mathrm{P}} \times \mathrm{P}=\mathrm{E} \times \mathrm{S} \times \mathrm{A} \times \mathrm{U} \times \mathrm{P}
$$

...where $C$ represents agricultural carbon emissions; AI signifies gross output value of farming industry; $A G$ denotes gross output value of farming, forestry, animal husbandry, and fishery; AP is total population; and $P$ is agricultural population.

$\mathrm{E}=\mathrm{CO}_{2} / \mathrm{AI}$ refers to production efficiency and reflects the relationship between desirable and undesirable outputs, i.e., carbon emissions.

$\mathrm{S}=\mathrm{AI} / \mathrm{AG}$ represents industry structure, namely the ratio of gross output value of farming to that of farming, forestry, animal husbandry, and fishery. Specifically, what should be emphasized is in order to study the link between agricultural carbon emissions and macroeconomics, also in conjunction with actual conditions of Hebei Province, the previous indicator $S$ is replaced by a new one, that is the ratio of gross output value of farming, forestry, animal husbandry, and fishery to regional gross output value of Hebei Province. After this replacement it can reflect the core of industrial structure better.

$A=A G / A P$ illustrates the affluence, i.e., agricultural output value per capita.

$\mathrm{U}=\mathrm{AP} / \mathrm{P}$ refers to urbanization level, which is not the same as traditional description [35] - the percentage of urban population to total population - but has the identical change direction. $P$ is agricultural population.

The extended STIRPAT model is shown in Eq. (7) and the logarithmic form shown in Eq. (8):

$$
C=\mathrm{aE}^{\mathrm{b}_{1}} \mathrm{~S}^{\mathrm{b}_{2}} \mathrm{~A}^{\mathrm{b}_{3}} \mathrm{U}^{\mathrm{b}_{4}} \mathrm{P}^{\mathrm{b}_{5}} \mathrm{e}
$$


Table 4. Descriptions of variables in this paper.

\begin{tabular}{|c|c|c|c|}
\hline Variables & Symbol & Definition & Unit \\
\hline Carbon emissions & $\mathrm{C}$ & Agricultural carbon emissions accounting & 10,000 tons \\
\hline Production efficiency & E & $\begin{array}{l}\text { Ratio of carbon emissions to gross output value of farming } \\
\text { industry }\end{array}$ & Ton $\mathrm{C} / 10,000$ yuan \\
\hline Industry structure & $\mathrm{S}$ & $\begin{array}{l}\text { Percentage of gross output value of farming, forestry, animal } \\
\text { husbandry, and fishery to regional gross output value of Hebei } \\
\text { Province }\end{array}$ & $\%$ \\
\hline Affluence & A & Agricultural output value per capita & $\begin{array}{l}10,000 \text { yuan per } \\
\text { capita }\end{array}$ \\
\hline Urbanization & $\mathrm{U}$ & Ratio of total population to agricultural population & $\%$ \\
\hline Population & $\mathrm{P}$ & Agricultural population & 10,000 people \\
\hline Agricultural machinery & M & Total power of farm machinery & $10,000 \mathrm{kw}$ \\
\hline Disaster degree & $\mathrm{D}$ & Proportion of the damage area to the overall arable area & $\%$ \\
\hline $\begin{array}{l}\text { Degree of opening to the } \\
\text { outside }\end{array}$ & $\mathrm{O}$ & $\begin{array}{l}\text { Proportion of agricultural import value to agricultural gross } \\
\text { output value }\end{array}$ & $\%$ \\
\hline
\end{tabular}

$$
\begin{aligned}
\ln C= & a+b_{1} \ln E+b_{2} \ln S+b_{3} \ln A+ \\
& +b_{4} \ln U+b_{5} \ln P+\ln e
\end{aligned}
$$

In addition, more affecting factors are allowed to be introduced. To verify whether there is a relationship of the Environmental Kuznets Curve (EKC) between carbon emissions and economic development, the $\ln \mathrm{A}$ term can be separated into two parts: $\ln \mathrm{A}$ and $(\ln \mathrm{A})^{2}$. It is the inverted U-shaped EKC that will exist if the coefficient of square term- $(\ln A)^{2}$ is negative [36]. Meanwhile, extensive application of agricultural machines to farming is a significant source of carbon emissions as well, usually described by total power of farm machinery, denoted by $M$, reflecting the technology level. Furthermore, agricultural disaster degree (the proportion of the damage area to the overall arable area) may have an effect on carbon emissions by reducing the yield of concerning crops, denoted by $\mathrm{D}$. Last but not least, the agricultural degree of opening to the outside (the proportion of agricultural import value to agricultural gross output value) can also influence carbon emissions, as denoted by O [37]. Generally, the more the import, the less carbon emissions, because local agricultural yield squeezed by the import is to indirectly diminish carbon emissions caused by local crop planting. A description of each variable is listed in Table 4. In summary, the final extended STIRPAT model is shown as follows:

$$
\begin{gathered}
\ln C=a+b_{1} \ln E+b_{2} \ln S+b_{31} \ln A+ \\
+b_{32}(\ln A)^{2}+b_{4} \ln U+b_{5} \ln P+b_{6} \ln M+ \\
+b_{7} \ln D+b_{8} \ln O+\ln e
\end{gathered}
$$

\section{Data Collection}

All data covering the period 1995-2014 were derived from the China Statistical Yearbook, the China Rural Statistical Yearbook, the Hebei Economic Yearbook, and the Hebei Rural Statistical Yearbook. Economic data, including regional gross output value and gross output value of farming, forestry, animal husbandry, and fishery were calculated by constant prices of 1995 to eliminate the side-effect of inflation.

\section{Empirical Analysis}

\section{Calculating Results of Carbon Emissions and Analysis}

Based on Eq. (1), the quantity of agricultural carbon emissions of Hebei Province from 1995 to 2014 is shown in Table 5. The changing tendency of agricultural carbon emissions from 1995 to 2014 and the varying proportion of each emission source to total agricultural carbon emissions are shown in Figs 1 and 2.

What is shown in Fig. 1 indicates that agricultural carbon emissions of Hebei Province have overall increased with fluctuations since 1995, and the quantity of those in 2010 was 93.006 thousand tons, reaching its peak value, but nevertheless declining from 2011 to 2014 . More concretely, the increment speed of agricultural carbon emissions from 1995 to 2004 is comparatively slow, with an annual growth rate of $4.13 \%$. The reason for this trend is that the level of agriculture mechanization was not very developed then, leading to small amounts of energy consumption, and the overuse of pesticide and chemical fertilizer was less severe. From 2004 to 2014, by contrast, although carbon emissions of some years decreased, the increasing velocity of those rose obviously 
Table 5. Agricultural carbon emissions in Hebei Province, 1995-2014 (10,000 tons).

\begin{tabular}{|c|c|c|c|c|c|c|c|c|c|c|}
\hline Year & $\begin{array}{c}\text { Total } \\
\text { carbon } \\
\text { emissions }\end{array}$ & $\begin{array}{l}\text { Growth } \\
\text { rate } \%\end{array}$ & $\begin{array}{l}\text { Agricultural } \\
\text { land use }\end{array}$ & $\begin{array}{l}\text { Growth } \\
\text { rate } \%\end{array}$ & $\begin{array}{l}\text { Paddy } \\
\text { field }\end{array}$ & $\begin{array}{l}\text { Growth } \\
\text { rate } \%\end{array}$ & Livestock & $\begin{array}{l}\text { Growth } \\
\text { rate } \%\end{array}$ & Energy & $\begin{array}{l}\text { Growth } \\
\text { rate } \%\end{array}$ \\
\hline 1995 & 464.63 & ----- & 263.90 & ------ & 13.50 & ------ & 8.06 & ------ & 179.18 & ------ \\
\hline 1996 & 499.97 & 7.61 & 295.56 & 12.00 & 14.87 & 10.18 & 8.29 & 2.85 & 181.25 & 1.16 \\
\hline 1997 & 526.17 & 5.24 & 300.59 & 1.70 & 16.28 & 9.52 & 8.64 & 4.21 & 200.66 & 10.71 \\
\hline 1998 & 531.93 & 1.09 & 309.30 & 2.90 & 16.06 & -1.35 & 9.22 & 6.69 & 197.48 & -1.58 \\
\hline 1999 & 566.73 & 6.54 & 312.42 & 1.01 & 16.22 & 0.98 & 9.59 & 4.06 & 228.60 & 15.76 \\
\hline 2000 & 566.06 & -0.12 & 313.49 & 0.34 & 15.09 & -6.98 & 9.65 & 0.65 & 227.94 & -0.29 \\
\hline 2001 & 586.71 & 3.65 & 320.14 & 2.12 & 9.87 & -34.61 & 9.86 & 2.13 & 247.12 & 8.41 \\
\hline 2002 & 641.21 & 9.29 & 328.28 & 2.54 & 11.64 & 17.96 & 9.80 & -0.65 & 291.78 & 18.07 \\
\hline 2003 & 641.76 & 0.09 & 339.69 & 3.47 & 7.93 & -31.89 & 10.24 & 4.49 & 284.21 & -2.59 \\
\hline 2004 & 668.89 & 4.23 & 353.86 & 4.17 & 8.76 & 10.45 & 10.95 & 6.97 & 295.66 & 4.03 \\
\hline 2005 & 770.48 & 15.19 & 372.17 & 5.17 & 9.20 & 5.03 & 11.36 & 3.76 & 378.13 & 27.89 \\
\hline 2006 & 788.75 & 2.37 & 373.52 & 0.36 & 9.30 & 1.14 & 7.28 & -35.90 & 399.07 & 5.54 \\
\hline 2007 & 827.26 & 4.88 & 382.11 & 2.30 & 8.86 & -4.74 & 6.81 & -6.43 & 429.92 & 7.73 \\
\hline 2008 & 853.92 & 3.22 & 384.85 & 0.72 & 8.55 & -3.55 & 6.68 & -2.04 & 454.29 & 5.67 \\
\hline 2009 & 895.98 & 4.93 & 390.16 & 1.38 & 8.97 & 4.91 & 6.41 & -3.97 & 490.82 & 8.04 \\
\hline 2010 & 930.06 & 3.80 & 395.07 & 1.26 & 8.36 & -6.78 & 5.98 & -6.72 & 521.09 & 6.17 \\
\hline 2011 & 927.90 & -0.23 & 400.03 & 1.26 & 8.70 & 4.14 & 6.01 & 0.42 & 514.18 & -1.33 \\
\hline 2012 & 926.33 & -0.17 & 405.29 & 1.31 & 9.01 & 3.49 & 5.97 & -0.63 & 507.06 & -1.38 \\
\hline 2013 & 848.13 & -8.44 & 412.44 & 1.77 & 9.10 & 1.05 & 5.95 & -0.26 & 421.66 & -16.84 \\
\hline 2014 & 894.52 & 5.47 & 417.32 & 1.18 & 8.89 & -2.30 & 6.08 & 2.16 & 463.26 & 9.87 \\
\hline
\end{tabular}

on the whole, and the annual growth rate was 5.25\%. The maximum of growth rate of agricultural carbon emissions appeared in 2005, resulting in growth rate increasing by $15.19 \%$ compared with 2004 . What can explain this rising tendency is that the liberation to productive forces accelerated the rapid development of agricultural economy, and the enlargement of scale of agricultural machinery sparked off substantial combustion of fossil fuels. It was in 2013, which saw the greatest reduction in 20 years (1995-2014), that the agricultural carbon emissions diminished to 84.813

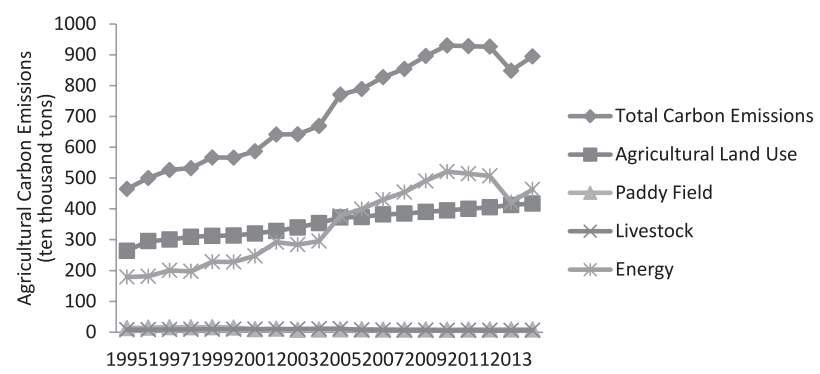

Fig. 1. Changes in agricultural carbon emissions of Hebei from 1995 to 2014 thousand tons, because the local government has spared no effort to conserve the ecological environment to reduce carbon emissions so that agricultural ones have lessened recently.

As is shown in Fig. 2, from the sectional perspective energy consumption and agricultural land use had remained leading parts in carbon sources in the past 20 years (1995-2014), accounting for approximately $90 \%$ of total agricultural carbon emissions. In addition, energy-

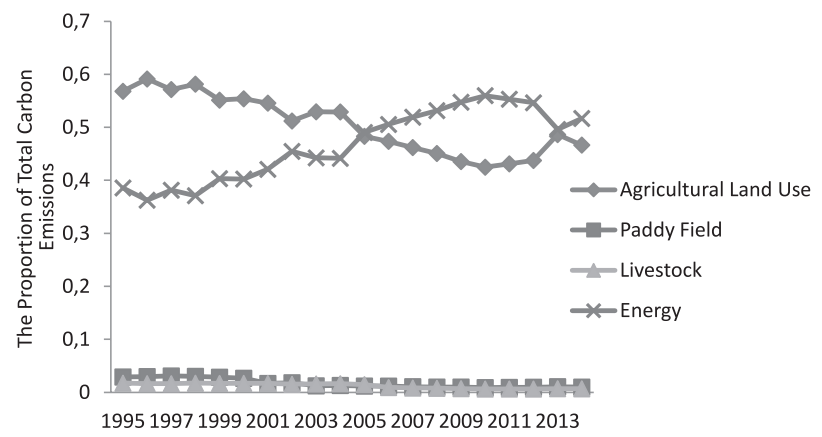

Fig. 2. Changes in proportion of each emission source to total agricultural carbon emissions. 
Table 6. Correlation results.

\begin{tabular}{|c|c|c|c|c|c|c|c|c|c|c|}
\hline & $\ln \mathrm{C}$ & $\ln \mathrm{E}$ & $\ln \mathrm{S}$ & $\ln \mathrm{A}$ & $(\ln \mathrm{A})^{2}$ & $\ln \mathrm{U}$ & $\ln \mathrm{P}$ & $\operatorname{lnM}$ & $\ln \mathrm{l}$ & $\operatorname{lnO}$ \\
\hline $\ln \mathrm{C}$ & 1.000 & .123 & -.778 & .806 & -.815 & .964 & .883 & .963 & -.700 & .925 \\
\hline $\ln \mathrm{E}$ & .123 & 1.000 & -.123 & -.465 & .444 & .024 & -.291 & .147 & .169 & .126 \\
\hline $\ln \mathrm{S}$ & -.778 & -.123 & 1.000 & -.563 & .576 & -.739 & -.605 & -.752 & .281 & -.618 \\
\hline $\ln \mathrm{A}$ & .806 & -.465 & -.563 & 1.000 & -.999 & .831 & .944 & .764 & -.767 & .755 \\
\hline$(\ln \mathrm{A})^{2}$ & -.815 & .444 & .576 & -.999 & 1.000 & -.830 & -.936 & -.765 & .771 & -.761 \\
\hline $\ln \mathrm{U}$ & .964 & .024 & -.739 & .831 & -.830 & 1.000 & .916 & .980 & -.709 & .904 \\
\hline $\ln \mathrm{P}$ & .883 & -.291 & -.605 & .944 & -.936 & .916 & 1.000 & .876 & -.735 & .854 \\
\hline $\ln \mathrm{M}$ & .963 & .147 & -.752 & .764 & -.765 & .980 & .876 & 1.000 & -.658 & .900 \\
\hline $\ln \mathrm{D}$ & -.700 & .169 & .281 & -.767 & .771 & -.709 & -.735 & -.658 & 1.000 & -.740 \\
\hline $\ln \mathrm{O}$ & .925 & .126 & -.618 & .755 & -.761 & .904 & .854 & .900 & -.740 & 1.000 \\
\hline
\end{tabular}

Table 7. Ordinary least squares estimation results.

\begin{tabular}{|c|c|c|c|c|c|c|c|c|c|c|}
\hline \multirow{2}{*}{ Model } & \multicolumn{2}{|c|}{$\begin{array}{l}\text { Unstandardized coef- } \\
\text { ficients }\end{array}$} & \multirow{2}{*}{$\begin{array}{c}\begin{array}{c}\text { Standardized } \\
\text { coefficients }\end{array} \\
\text { Beta }\end{array}$} & \multirow{2}{*}{$\mathrm{t}$} & \multirow{2}{*}{ Sig. } & \multicolumn{3}{|c|}{ Correlations } & \multicolumn{2}{|c|}{ Collinearity statistics } \\
\hline & B & Std. Error & & & & Zero-order & Partial & Part & Tolerance & VIF \\
\hline Constant & -48.386 & 23.453 & & -2.063 & .066 & & & & & \\
\hline $\ln E$ & .536 & .210 & .422 & 2.556 & .029 & .123 & .629 & .072 & .029 & 34.565 \\
\hline $\ln S$ & -.123 & .051 & -.159 & -2.418 & .036 & -.778 & -.607 & -.068 & .183 & 5.474 \\
\hline $\ln \mathrm{A}$ & -1.526 & 2.356 & -1.390 & -.648 & .532 & .806 & -.201 & -.018 & .000 & 5849.366 \\
\hline$(\ln A)^{2}$ & -.616 & .674 & -1.678 & -.914 & .382 & -.815 & -.278 & -.026 & .000 & 4288.167 \\
\hline $\ln U$ & 3.787 & 2.378 & .345 & 1.593 & .142 & .964 & .450 & .045 & .017 & 59.645 \\
\hline $\ln \mathrm{P}$ & 6.416 & 2.545 & .599 & 2.521 & .030 & .883 & .623 & .071 & .014 & 71.659 \\
\hline $\ln M$ & -.257 & .198 & -.284 & -1.300 & .223 & .963 & -.380 & -.036 & .017 & 60.437 \\
\hline $\ln \mathrm{D}$ & -.021 & .037 & -.036 & -.580 & .575 & -.700 & -.180 & -.016 & .210 & 4.772 \\
\hline $\ln \mathrm{O}$ & -.014 & .027 & -.048 & -.495 & .631 & .925 & -.155 & -.014 & .085 & 11.804 \\
\hline
\end{tabular}

$\mathrm{R}^{2}=0.992$, F-statistic $=140.027$, Sig.F $=0$.

related carbon emissions had almost the same changing tendency as that of overall carbon emissions, and was invariably less than those of agricultural land use from 1995 to 2003, then playing a leading role since 2003 owing to its rapid growth. As for agricultural land use, carbon emissions from that had risen steadily with an annual growth rate of $2.45 \%$ since 1995 , while the percentage of that has declined with small fluctuations: the percentage of carbon emissions arising from land use was always the most from 1995 to 2005, but coincident with a decrease of arable land area on account of soil erosion and the like has been a drop of the percentage of carbon emissions from agricultural land use. Last but not least, carbon emissions of paddy and livestock, in a comparatively tiny proportion of the whole, has been reduced in general, which can be attributed to technological innovation and general mechanization.

\section{Regression Results}

On the basis of data collected, SPSS Software 23.0 was utilized to make multiple linear regression analysis of Eq. (9), and the results can be seen in Tables 6 and 7. As shown above, even though $\mathrm{R}^{2}$ (goodness of fit) is $0.992, \mathrm{~F}$ test statistic 140.027, and $\mathrm{P}$ value 0.000 , Table 6 demonstrates a strong correlation among variables such as correlation coefficient between $\ln \mathrm{A}$ and $\ln \mathrm{P}$ being 0.944 and 0.916 , between $\ln U$ and $\ln \mathrm{P}$. As a result, multicollinearity may exist. Moreover, by testing variance inflation factor (VIF) in Table 7, only VIF values of $\ln S$ and $\ln \mathrm{D}$ are smaller than 10 and the rest are all bigger than 10, such as $\ln \mathrm{A}$. VIF of it reaches 5849, showing serious multicollinearity among variables. Accordingly, it proves to be invalid and employs the ordinary least squares (OLS) method to have an unbiased estimate of coefficients of independent variables. 


\section{Ridge Regression Theory}

As we know, the formula for multiple linear regression is given by

$$
\mathrm{Y}=\mathrm{X} \beta+\varepsilon
$$

...where $\mathrm{Y}$ represents an $(\mathrm{n} \times 1)$ matrix of dependent variables, $\mathrm{X}$ notes an $(\mathrm{n} \times \mathrm{p})$ matrix of independent ones, $\beta$ is a $(p \times 1)$ vector of unknown coefficients, and $\varepsilon$ refers to the normally distributed random errors with the assumptions of zero-mean and equal variance. Using the OLS regression, the unbiased estimation of $\beta$ can be written as

$$
\beta=\left(\mathrm{X}^{\mathrm{T}} \mathrm{X}\right)^{-1} \mathrm{X}^{\mathrm{T}} \mathrm{Y}
$$

The $\hat{\beta}$, however, will become terribly unstable if serious multicollinearity exists among independent variables, leading to large errors with realistic value of $\beta$ and even mathematical signs inconsistent with actual economic meaning [38]. To address the invalidity caused by multicollinearity to utilize the OLS method, ridge estimation was put forward by Hoerl in 1962, and he further elaborated upon it with Kennard in 1970 [39]. The quintessence of ridge regression estimation is that when multicollinearity occurs among independent variables, i.e., $|\mathrm{XTX}| \sim 0$, a normal matrix $\mathrm{kI}(\mathrm{k}>0$, I is a unit matrix $)$ plus XTX becomes XTX+kI, which is not closer to a singular matrix ever.

Eq. (12) is called the ridge regression of $\beta$ :

$$
\hat{\beta}(k)=\left(X^{T} X+k I\right)^{-1} X^{T} Y
$$

...where $\mathrm{k}$ is called ridge parameter.

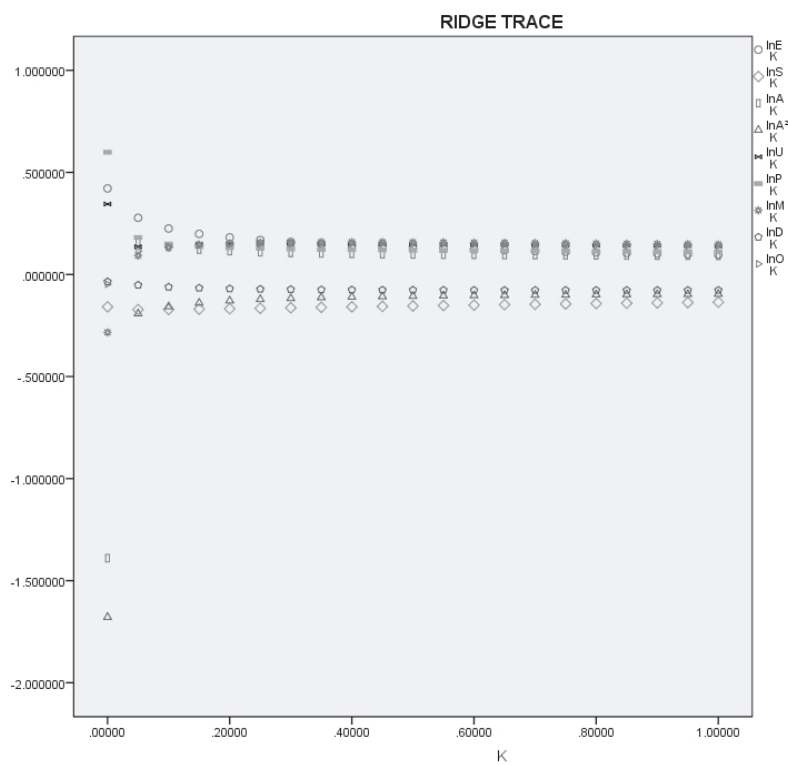

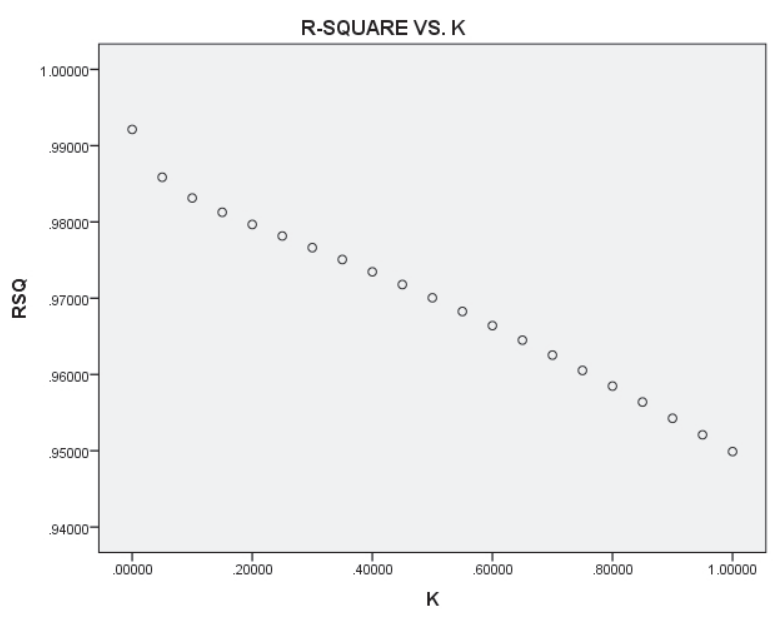

Fig. 4. Relationship between $\mathrm{K}$ and $\mathrm{R}^{2}$.

It is apparent that $\hat{\beta}(\mathrm{k})$ is not the unbiased estimation of $\beta$ anymore, which shows characteristics of ridge regression that sacrifice unbiasedness to acquiring a more realistic equation.

\section{Ridge Regression Estimation}

Ridge regression analysis in Eq. (9) and consequences can be seen in Figs 3 and 4. First, select independent variables with the help of ridge trace. As is shown in Fig. 3, relatively small is the absolute value of ridge regression coefficient of $\mathrm{lnD}$, stable around the zero axis. According to principles of variables selection based on ridge estimation [40], $\ln \mathrm{D}$ representing disaster degree of arable land can be got rid of, and it seems that disaster for agriculture in Hebei Province has little impact on carbon emissions. The remaining variables are retained for ridge trace of those become stable as ridge parameter $\mathrm{k}$ increases. Meanwhile, the absolute values of ridge coefficient are not very small. What's more, in line with Fig. 4, when $\mathrm{k}=0.2$, ridge regression coefficients all head for stability, with $\mathrm{R}^{2}$ being 0.98 , illustrating the excellent goodness of fit of the equation. Thus, choose $\mathrm{k}=0.2$ to make ridge regression anew, and ridge regression results are shown in Tables 8-10. The formula equation based on ridge regression is as follows:

$$
\begin{gathered}
\ln C=-7.0837+0.2356 \ln E-0.1144 \ln S \\
+0.1442 \ln \mathrm{A}-0.0543(\ln \mathrm{A})^{2}+1.7529 \ln \mathrm{U}+ \\
1.4251 \ln \mathrm{P}+1.4265 \ln \mathrm{M}+0.0471 \ln \mathrm{O}
\end{gathered}
$$

The standardized one is:

$$
\begin{gathered}
\ln C=0.1852 \ln E-0.1475 \ln S+0.1314 \ln \mathrm{A} \\
-0.1479(\ln \mathrm{A})^{2}+0.1597 \ln \mathrm{U}+0.1329 \ln \mathrm{P} \\
+0.1573 \ln \mathrm{M}+0.1663 \ln \mathrm{O}
\end{gathered}
$$

Fig. 3. Ridge trace 
Table 8 . Model summary.

\begin{tabular}{|c|c|c|c|c|}
\hline Model & Mult R & R square & Adj RSqu & SE \\
\hline 1 & .9894971665 & .9791046425 & .9639080189 & .0449510800 \\
\hline
\end{tabular}

Table 9. ANOVA.

\begin{tabular}{|c|c|c|c|c|c|}
\hline Model & df & SS & MS & F value & Sig F \\
\hline Regress & 8.000 & 1.041 & .130 & 64.42909073 & .00000004 \\
\hline Residual & 11.000 & .022 & .002 & & \\
\hline
\end{tabular}

Table 10. Ridge estimation results.

\begin{tabular}{|c|c|c|c|c|c|}
\hline Variables & $\mathrm{B}$ & $\mathrm{SE}(\mathrm{B})$ & $\mathrm{Beta}$ & $\mathrm{T}$ & $\mathrm{Sig}$ \\
\hline $\ln \mathrm{C}$ & .235631970 & .043278008 & .185184226 & 5.444612190 & .000202482 \\
\hline $\ln \mathrm{S}$ & -.114424760 & .032910443 & -.147482838 & -3.476852677 & .005177074 \\
\hline $\ln \mathrm{A}$ & .144244493 & .024233406 & .131396715 & 5.952299538 & .000095605 \\
\hline$(\ln \mathrm{A})^{2}$ & -.054262127 & .010190559 & -.147892490 & -5.324744852 & .000243017 \\
\hline $\ln \mathrm{U}$ & 1.752916895 & .328862098 & .159732821 & 5.330249080 & .000240979 \\
\hline $\ln \mathrm{P}$ & 1.425054901 & .333264987 & .132993531 & 4.276041463 & .001307364 \\
\hline $\ln \mathrm{M}$ & .142651996 & .026411985 & .157315976 & 5.401032714 & .000216320 \\
\hline $\ln \mathrm{N}$ & .047108145 & .011640751 & .166337899 & 4.046830528 & .001925926 \\
\hline Constant & -7.083733133 & 2.927396839 & .000000000 & -2.419806238 & .034018558 \\
\hline
\end{tabular}

\section{Ridge Regression Results Analysis}

Because of diverse units of variables, the standardized regression coefficient indicating the changing percentage of dependent variables induced by $1 \%$ change of independent variables is taken advantage of for comparing every influential factor at an identical level.

According to Eq. (14), driving factors of agricultural carbon emissions could be ranked based on their influenced degrees reflected by standardized regression coefficients as follows: production efficiency (lnE) $>$ agricultural degree of opening to the outside $(\operatorname{lnO})>$ urbanization $(\ln U)>$ total power of farm machinery $(\ln M)>$ industry structure $(\ln S)>$ agricultural population $(\ln P)>$ agricultural output value per capita $(\ln \mathrm{A})$.

Production efficiency is the primary driving factor promoting agricultural carbon emissions, which reflects the utilization ratio of agricultural materials (chemical fertilizer, pesticide, plastic sheeting, etc.) and 1\% growth in that will cause $0.1852 \%$ growth in carbon emissions, because the meaning of this indicator - the ratio of carbon emissions to gross output value of the farming industry is inverse to actual efficiency. The application amount of chemical fertilizer per planting area has increased with an average annual rate of $0.6 \%$, and pesticides with an annual growth rate of $0.5 \%$ [11], leading to more carbon emissions caused by their overuse. As we know, the more those are utilized, the less the actual agricultural productive efficiency, explaining why this coefficient is positive.

The degree of opening to the outside is another crucial factor fueling a positive impact, indicating a $0.1663 \%$ increase in carbon emissions due to a $1 \%$ increase in import degree, which is inconsistent with the former study by other scholars. For example, Wu et al. [37] believed that the enhancement of import would squeeze the local output of crops. Consequently, carbon emissions in its growth can be reduced. Aimed at this contradiction, a report issued by the Institut National de la Statistique et des Études Économiques (INSEE) said in terms of carbon footprint, not only in the course of agricultural production did agricultural products import influence carbon emissions, but also the process in which relevant raw material and semi-finished products are transported to Hebei cities and products returned to countries of origin produced energy consumption that could accelerate carbon emissions from import [41]. It is obvious that the proportion of agricultural products import is minute in Hebei Province - a large traditional agricultural province. The percentage of import value was $0.3 \%$ on average from 2010 to 2014 [9]. The resulting decrease of carbon emissions by import is probably far less than their increase by transportation. 
Urbanization has a decisive influence on carbon emissions as well, accounting for a $0.1597 \%$ increase in carbon emissions owing to a $1 \%$ increase in urbanization level, which confirms Liu [20]. Urbanization level in this paper means the ratio of total population to agricultural population, which changes in the same direction with orthodox meaning of that (the proportion of urban population to total population). As the advancement of the economy flourishes, urbanization in Hebei Province also progresses with swift speed. The urbanization rate increased from $17.29 \%$ in 1995 to $49.33 \%$ in 2014, with an annual growth rate of $5.67 \%$, the boost of which can be conducive toward great establishment of agricultural infrastructure in a short time and increasing demand for updated modern equipment from farmers, both directly leading to substantial energy consumption and environmental pollution, moreover plentiful carbon emissions. However, there is a gap of urbanization to some extent between Hebei Province and China, whose urbanization rate is $54.77 \%$ on average according to recent statistics [42]. Economic development must encourage the process of urbanization. So how to coordinate carbon emission reduction with the urbanization process will lay great emphasis on sustainable development on Hebei Province agriculture.

Another contributing factor of agricultural carbon emissions is agricultural mechanization level. Based on Eq. (14), carbon emissions will increase by $0.1573 \%$ when the total power of farm machinery increases by $1 \%$. Agricultural machinery refers to the kind of machines used for farming production and the preliminary process for agricultural and livestock products in planting industry and animal husbandry. By means of diesel oil or other kinds of fossil fuel as power, agricultural machinery will certainly bring about prominent carbon emissions during its exertion. The total power of farm machinery increased from 4336.44 ten thousand $\mathrm{kw}$ in 1995 to 10942.86 ten thousand $\mathrm{kw}$ in 2014, rising by $152 \%$ in total, which demonstrates a remarkable boost in agricultural mechanization level resulted from technological improvement, whereas combustion level and work efficiency of such equipment has not obtained synchronized advancement so far, with the amount of carbon emissions from fossil fuel augmented.

Industrial structure characterized by the ratio of gross output value of farming, forestry, animal husbandry, and fishery to regional gross output value of Hebei Province, however, reveals a limited role in carbon emissions, explaining the $0.1475 \%$ decrease in carbon emissions due to its $1 \%$ growth. As a powerful agricultural province, the contribution rate of agriculture to regional output value of Hebei was $11.7 \%$ in 2014 , higher than that of the national average rate of $9.1 \%$, and the rate of farming employee population to total agricultural population of Hebei was $18.73 \%$ in 2014 , higher than that of the national average rate of $16.66 \%$. As a result, it is concluded that agricultural carbon emissions will be relieved to a certain degree on condition that the local government pays great attention to agricultural progress, and enlarges
Table 11. Elastic coefficients of agricultural output value per capita.

\begin{tabular}{|c|c|c|c|}
\hline Year & A & $\mathrm{EE}_{\mathrm{A}}$ & $\Delta \mathrm{EE}_{\mathrm{A}}$ \\
\hline 1995 & $1,783.175392$ & -2.083003461 & \\
\hline 1996 & $1,829.901645$ & -2.090654776 & -0.007651316 \\
\hline 1997 & $1,873.081033$ & -2.097553562 & -0.006898786 \\
\hline 1998 & $1,807.925381$ & -2.087080852 & 0.010472709 \\
\hline 1999 & $1,751.728042$ & -2.077740306 & 0.009340547 \\
\hline 2000 & $1,647.280518$ & -2.059555411 & 0.018184895 \\
\hline 2001 & $1,696.114615$ & -2.068197017 & -0.008641607 \\
\hline 2002 & $1,652.138935$ & -2.060426546 & 0.007770471 \\
\hline 2003 & $1,749.957165$ & -2.077441121 & -0.017014575 \\
\hline 2004 & $1,979.204561$ & -2.113855201 & -0.036414079 \\
\hline 2005 & $2,022.524196$ & -2.120259657 & -0.006404456 \\
\hline 2006 & $1,805.800832$ & -2.086733044 & 0.033526613 \\
\hline 2007 & $2,152.590013$ & -2.138695522 & -0.051962478 \\
\hline 2008 & $2,319.774606$ & -2.160820846 & -0.022125324 \\
\hline 2009 & $2,319.080238$ & -2.160732292 & 0.000088553 \\
\hline 2010 & $2,593.190333$ & -2.19377855 & -0.033046258 \\
\hline 2011 & $2,818.39571$ & -2.218412454 & -0.024633904 \\
\hline 2012 & $2,935.602562$ & -2.230464798 & -0.012052344 \\
\hline 2013 & $3,085.481246$ & -2.245194132 & -0.014729333 \\
\hline 2014 & $3,028.206394$ & -2.239651684 & 0.005542448 \\
\hline
\end{tabular}

technological input and innovation in this realm such as devoting major efforts to implementation of low-carbon agriculture.

Population is also responsible for the rise in carbon emissions, explaining the $0.1329 \%$ growth that corresponds to a $1 \%$ growth in population. There exists a positive correlation between agricultural population and carbon emissions owing to the absolute demand for resources from mankind. As agricultural population has been decreased with the promotion of urbanization in Hebei Province, it can restrain carbon emissions stemming from the population factor to some extent. But the influence induced by agricultural population on carbon emissions remains to be seen in the wake of gradual implementation of "the universal two-child policy" in China that all couples regardless of urban and rural areas, regions, and nationalities, can give birth to two children [43].

Agricultural output value per capita also plays an important role in carbon emissions. To begin with, the coefficient of $(\ln \mathrm{A})^{2}$ is negative according to Eq. (14), showing that there is an EKC reflecting the relationship between affluence factor and agricultural carbon emissions. Agricultural economic acceleration can bring about the inflection point of carbon emissions while the 
definite position needs further study to ascertain. And the elastic coefficient of this affluence factor can be calculated based on Eq. (14). The first-order derivative of $\ln \mathrm{A}$ to $\ln \mathrm{C}$ is as follows:

$$
\mathrm{EE}_{\mathrm{A}}=0.1314-0.2958 \ln \mathrm{A}
$$

...where EEA represents the elastic coefficients of each value of A, shown in Table 11.

Table 11 reveals that all values of elastic coefficient are negative, which illustrates that carbon emissions present a diminished trend with the augmentation of agricultural output value per capita, because Hebei Province has transformed the agricultural mode of development recently. Since 2013 the most severe environmental pollution in Hebei's history has erupted in the form of fog and haze. After that, conserving the eco-environment has become an indispensable part of economic advancement. Much research has proven that carbon emissions from agriculture would be a necessary contribution toward environmental problems. For this reason, the local government invests more in agricultural reform and innovation, and speeds up efforts to transform extensive agriculture to intensive. As shown in Fig. 2, agricultural carbon emissions at the end of 2013 totaled 894.5 ten thousand tons, the lowest value from 2010 to 2014. Although carbon emissions saw a rebound in 2014, the efforts that Hebei Province have taken to resolve this problem have achieved initial success, and it pays to make bigger efforts nevertheless. Table 11 also reveals that the absolute value of elastic coefficient increases and meanwhile the variation in elastic coefficient decreases as a whole following the growth in $\mathrm{A}$, because the rise of affluence can promote technological improvement that weakens carbon emissions.

\section{Conclusions and Policy Recommendations}

\section{Conclusions}

1) Driving factors that can promote carbon emissions are production efficiency, the degree of opening to the outside, urbanization, agricultural mechanization level, and agricultural population, whose $1 \%$ increase will cause $0.1852 \%, 0.1663 \%, 0.1597 \%, 0.1573 \%$, and $0.1329 \%$ increases in carbon emissions, respectively. And the restrained factors are industry structure and agricultural output value per capita, responsible for $0.1475 \%$ and $(0.1314-0.2958 \ln \mathrm{A}) \%$ decreases in carbon emissions with a $1 \%$ increase in those two factors.

2) Because of the regression coefficient of square term$(\ln \mathrm{A})^{2}$-negative, according to Wang [44], there exists an EKC revealing the inverted U-shaped relationship between economic progress and carbon emissions, testified to by the obvious reduction in 2013 shown in Fig. 1.

\section{Policy Recommendations}

Recently, the Hebei government spared no effort to handle an increasingly severe environmental situation, especially carbon emissions from agriculture. For accomplishing the aim to build ecological civilization of the 13th Five-Year Plan (2016-2020) [11], relevant measures forming low-carbon agriculture can be taken from the following three aspects:

1) Population. Urbanization should be boosted steadily and smoothly. As a traditional agricultural province, Hebei has a large population and base number of farmers, so that urbanization should follow the law of a regional objective economy instead of the blind pursuit of urbanization speed. Thus relevant departments ought to make overall plans by taking all factors into consideration: gradually transfer farmers from country to city and construct infrastructure based on a logical project, both beneficial to harmonious development among society, economy, and environment. Meanwhile, under the universal "twochild" policy, it would be helpful to control agricultural population size and encourage fewer and better births for farmers in order to achieve a healthy population structure. Furthermore, it is vital to strengthen low-carbon awareness of farmers and improve the quality and skill of agricultural employees so that they are to reduce their carbon footprint by appropriate behaviors daily, which will be of great help for the establishment of green and low-carbon agriculture in Hebei in the near future.

2) Economy. Hebei should give top priority to agricultural industry upgrading, converting production mode from resource-consuming to innovationpowered pattern. There will be also an urgent need for the government to optimize industrial structure, consolidate planting, promote animal husbandry, refine fishery, enrich agricultural products processing, cultivate leisure agriculture, and erect the logistics base for agricultural products to create a complete modern agricultural production system. Meanwhile as for agricultural opening-up, it is rewarding to heighten technological introduction, develop export-oriented agriculture, promoting "Internet plus" mode and, in addition, building an efficient agricultural "Internet of Things" (IOT) that not only exports agriculture products with distinctive local features efficiently but also ensures that it is an environmentally friendly process.

3) Technology. Priorities for the technological aspect should be increasing production efficiency of agriculture, enhancing technological upgrading of agricultural machines, and expanding the application of innovations in agricultural science and technology. Eleven provincial industrial technological innovative teams and five agricultural scientific innovative leagues should be supported in fund and policy persistently. The principle of low-carbon agriculture should be consolidated among farmers by propelling 
the popularization of pollution-free pesticides and green manure during farming, and spreading clean energy used for agricultural machines to replace fossil fuels.

\section{Acknowledgements}

This work was supported by the Social Science Foundation of China, forecasting of carbon emission peak and countermeasures for emission reduction under new normal conditions (No. 15BGL145). The authors would like to extend special thanks to the editors and the reviewers for their excellent comments and suggestions in improving the quality of our paper.

\section{References}

1. XIONG C., YANG D., HUO J., ZHAO Y. The Relationship between Agricultural Carbon Emissions and Agricultural Economic Growth and Policy Recommendations of a Lowcarbon Agriculture Economy. Polish Journal of Environmental Studies, 25 (5), 2016.

2. WEN L., LI Y. The Causality Relationships between Energy-related $\mathrm{CO}_{2}$ Emissions and its Influencing Factors with Linear and Nonlinear Granger Causality Tests. Polish Journal of Environmental Studies, 26 (3), 1313, 2017.

3. LIU Y., WEN L. The Peak Value of Carbon Emissions in the Beijing-Tianjin-Hebei Region Based on the STIRPAT Model and Scenario Design. Polish Journal of Environmental Studies, 25 (2), 2016.

4. WANG C., WANG F., SU Y., YE Y. Examining the driving factors of energy related carbon emissions using the extended STIRPAT model based on IPAT identity in Xinjiang. Renewable and Sustainable Energy Reviews, 67 (January), 51, 2017.

5. XINHUANET. The Standing Committee of the National People's Congress approved The Paris Agreement. Retrieved July 6, 2017, from http://news.xinhuanet.com/ politics/2016-09/03/c_129268519.htm 2016.

6. XIONG C., YANG D., HUO J. Spatial-Temporal Characteristics and LMDI-Based Impact Factor Decomposition of Agricultural Carbon Emissions in Hotan Prefecture, China. Sustainability, 8 (3), 262, 2016.

7. RAN G. Study on the Changing Tendency and Countermeasures of Carbon Emission Produced by Agricultural Production in China. Issues in Agricultural Economy, 2, 32, 2011.

8. HE Y., TIAN Y., ZHANG J. B. Analysis on Spatial-Temporal Difference and Driving Factors of Agricultural Carbon Emissions in Hubei Province. Journal of Huazhong Agricultural University, 5, 79, 2013.

9. Bureau of Statistics of Hebei. Hebei Rural Statistics Yearbook of 2016. Hebei Statistical Bureau: Hebei, China. 2016.

10. CAO Z., YANG J., ZHAO W. Rural Statistical Yearbook of Hebei Province. Hebei Statistical Bureau: Hebei, China. 2016.

11. LIU X., YANG J. The Thirteenth Five-Year Plan for Modern Agriculture Development in Hebei Province. Modern Agriculture, 13, 73, 2016.

12. DAI X., HE Y., ZHONG Q. Driving factors and their contributions to agricultural $\mathrm{CO}_{2}$ emission due to energy con- sumption in China-Based on an expended Kaya identity and LMDI decomposition method. Chinese Journal of EcoAgriculture, 23 (11), 1445, 2015.

13. YORK R., ROSA E. A., DIETZ T. STIRPAT, IPAT and ImPACT: analytic tools for unpacking the driving forces of environmental impacts. Ecological Economics, 46 (3), 351, 2003.

14. LI B., ZHANG J., LI H. Research on Spatial-temporal Characteristics and Affecting Factors Decomposition of Agricultural Carbon Emission in China. China Population Resources \& Environment, 13 (6), 1300, 2011.

15. YANG J. The Effects of Technological Advances on Agricultural Carbon Emission-Evidence from Chinese Provincial Data. Soft Science, 27 (10), 116, 2013.

16. YANG J. Analysis on regional difference and affecting factors of agriculture carbon emission in China. Journal of Henan Agricultural University, 3, 336, 2012.

17. LIU L. Research on Spatiotemporal Characteristics and Impact Factors Decomposition of Agricultural Carbon Emission in Henan Province. Research of Soil and Water Conservation, 21 (4), 179, 2014.

18. CAO J., CAO L. Research on Measurement and Effecting Factors of Agricultural Carbon Emission in Jiangxi Province. Ecological Economy, 32 (7), 66, 2016.

19. GAO B., FANG J., XU Q., LI Y. Dynamic Change and Analysis of Driving Factors of Agricultural Carbon Emissions in Jilin Province. Research of Agricultural Modernization, 34 (5), 617, 2013.

20. LIU L., XU J. Analysis of Influencing Factors of Agricultural Carbon Emission in Guangdong Province with the Extended STIRPAT Model. Science \& Technology Management Research. 2016V

21. YUAN Z.J., ZHANG J.J., FU Y. Temporal and Spatial Variation and Influence Factors of Carbon Source and Sink of Farmland Ecosystem in Hebei Province. Bulletin of Soil \& Water Conservation, 32 (6), 206, 2012.

22. XIE L. Study of Agricultural Sustainable Development Based on the Irrigation Efficiency and the Carbon Footprint in Hebei Province. Hebei University of Science and Technology. 2015V

23. LU J., GAO F., JIAO X., ZHANG C. Analysis Between Agricultural Products and Economic Development in Hebei Province from Low Carbon Perspective. Heilongjiang Animal Science and Veterinary Medicine, 14, 1, 2014.

24. TIAN J., YANG H., XIANG P., LIU D., LI, L. Drivers of agricultural carbon emissions in Hunan Province, China. Environmental Earth Sciences, 75 (2), 1, 2016.

25. MIN J.S., HU H. Calculation of Greenhouse Gases Emission from Agricultural Production in China. China Population Resources \& Environment, 22 (7), 21, 2012V

26. LI Y., LIN E., ZHEN X.L. Advances in Methods of Agricultural Greenhouse Gas Inventories. Advances in Earth Science, 2, 335, 2007.

27. WANG M., LI J., ZHENG X. Methane Emission and Mechanisms of Methane Production, Oxidation, Transportation in the Rice Fields. Scientia Atmospherica Sinica, 22 (4), 600, 1998.

28. PACHAURI R.K., MEYER L.A. IPCC, 2014: Climate Change 2014: Synthesis Report. Contribution of Working Groups I, II and III to the Fifth Assessment Report of the Intergovernmental Panel on Climate Change. 2014

29. EGGLESTON S., BUENDIA L., MIWA K., NGARA T., TANABE K. 2006 IPCC Guidelines for National Greenhouse Gas Inventories. Volume 4 Agriculture, Forestry and Other Land Use. 2006. 
30. EHRLICH P.R., HOLDREN J.P. Impact of population growth. Science, 171 (3977), 1212, 1971.

31. DIETZ T., ROSA E.A. Rethinking the environmental impacts of population, Affluence and technology. Human Ecology Review, 1 (2), 277, 1994.

32. WANG Z. An empirical research on the influencing factors of regional $\mathrm{CO}_{2}$ emission : evidence from Beijing City, China. Applied Energy, 100 (4), 277, 2012.

33. SOULE P.T., DEHART J.L. Assessing IPAT Using Production- and Consumption-based Measures of I. Social Science Quarterly, 79 (4), 754, 1998.

34. KAYA Y. Impact of Carbon Dioxide emission control on GNP growth: Interpretation of proposed scenarios. In Paper presented to the IPCC Energy and Industry Subgroup, Response Strategies Working Group. 1990.

35. HUANG R., WANG Z. Influencing factors of carbon emissions from energy consumptions in Chongqing based on STIRPAT model. Acta Scientiae Circumstantiae, 33 (2), 602, 2013.

36. CHEN C.C., LIU C.L., HAO W. Examining the impact factors of energy consumption related carbon footprints using the STIRPAT model and PLS model in Beijing. Zhongguo Huanjing Kexue/china Environmental Science, 34 (6), $1622,2014$.

37. WU X., ZHANG J., TIAN Y., LI P. Provincial Agricultural Carbon Emissions in China: Calculation, Performance Change and Influencing Factors. Resources Science, 36 (1), 129, 2014.

38. GUNST R.F., WEBSTER J.T. Regression analysis and problems of multicollinearity. Journal of Genetics \& Molecular Biology, 7 (4), 277, 1975.
39. HOERL A.E., KENNARD R.W. Ridge Regression: Applications to Nonorthogonal Problems. Technometrics, 12 (1), 69, 1970.

40. DRAPER N.R., SMITH H. Ridge Regression. John Wiley \& Sons, Inc. 2014.

41. HAN Y., ZHANG L. Factors Decomposition of Agricultural Carbon Emissions in China Based on LMDI Model from Energy Consumption and Trade. Contemporary Economic Research, 4, 47, 2013.

42. NBSC. China Statistical Yearbook of 2016. China Statistics Press. 2016V

43. XINHUANET. China Fully Liberalized the Two- Children Policy. Retrieved July 11, 2017, from http://news.xinhuanet. com/health/2015-10/30/c_128374158.htm 2015.

44. WANG L. Analysis of spatial variations in environmental impact based on the STIRPAT model-A case study of energy consumption. Acta Scientiae Circumstantiae, 28 (5), 1032, 2008

45. TIAN Y., ZHANG J.B., HE Y. Research on Spatial-Temporal Characteristics and Driving Factor of Agricultural Carbon Emissions in China. Journal of Integrative Agriculture, 13 (6), 1393, 2014.

46. WU F., LI L., ZHANG H., CHEN F. Effects of conservation tillage on net carbon flux from farmland ecosystems. Chinese Journal of Ecology, 26 (12), 2035, 2007.

47. KUMAR P., MARTINO D., SMITH P. Agriculture (Chapter8) in IPCC, 2007: Climate change 2007: Mitigation of Climate Change. Contribution of Working Group III to the Fourth assessment Report of the Intergovernmental Panel on Climate Change. 2007. 
